\title{
Investigation of Background Gamma Radiation from Ceilings in Students' Hostels and Offices at the University of Maiduguri, Northeastern Nigeria
}

\author{
*Sonloye, Seyi . Fawole, Ibrahim.W. Mohammad, S. \\ Department of Physics, University of Maiduguri, Borno State, Nigeria
}

\begin{abstract}
Environmental radiation study forms a major aspect of radiation monitoring all over the world and Gamma radiation is the prime concern for radiation protection. Measurements of gamma radiation level were made using RADEYE PRD at selected Asbestos ceiling and non-asbestos (Gypsum) ceiling rooms in Block B and C of the Boys' Hostels and New Faculty of Art Building respectively. Annual dose rate from each selected location was then estimated and the results show that gamma radiations from rooms with asbestos ceilings are generally higher than those from rooms with non-asbestos ceilings. The higher radiation around the asbestos ceiling is attributed to likely presence of primordial radionuclides of elements like ${ }^{238} \mathrm{U},{ }^{232} \mathrm{Th}$ and ${ }^{40} \mathrm{~K}$ in the soil where the asbestos was mined. The highest annual effective dose rate due to gamma radiation in rooms with asbestos ceilings is estimated to be $0.91 \mathrm{mSv}$ per year. This is considered to be very low and insignificant to cause any serious radiological problem to the students living in the Hostel. However, the only possible health risks from asbestos ceilings rooms might be due to the toxicity of the chemical constituents of asbestos rather than radiological risks from natural gamma radiation. The outcome of this research can be used in the compilation of background radiation map and radioelement mapping of Maiduguri which will be an integral part of the national background radiation and radioelement mapping of Nigeria.
\end{abstract}

Keywords: gamma, radiation, carcinogenic, asbestos, radionuclides

DOI: $10.7176 /$ APTA/75-02

\section{Introduction}

The composition of the earth's crust is a major source of natural radiation. The main contributors are natural deposits of uranium, potassium and thorium which. These elements, in the process of natural decay, will release small amounts of ionizing radiation. Uranium and thorium are found essentially in soil and rocks in most parts of the world. Norbani et al., (2014) noted that naturally occurring radionuclides of Uranium, Thorium and Potassium are the main sources of radiation in soils and rocks from which traditional building materials are derived. International Atomic Energy Agency, (IAEA, 2004) observed that radionuclides in the ground emit penetrating gamma rays that irradiate us more or less uniformly. Since most building materials are extracted from the Earth, they too are mildly radioactive, and people are irradiated indoors as well as outdoors.

Asbestos is also a group of minerals that occur naturally as bundles of fibres found in soil and rocks in many parts of the world. But its good strength and excellent thermal properties as well as its resistance to chemical, thermal and biological degradation (NTP, 2005) made it suitable in construction industry as roofing shingles, ceilings and floor tiles among others (USGS, 2001; NTP, 2005; virta, 2006). This is because asbestos has been shown to induce fibrosis, lung cancer, mesothelioma, and probably other kinds of intestinal cancer diseases (Pastuszka, 2009; HSE, 2005). So if these asbestos are mined from soil or rocks that contain radionuclides of Uranium, Thorium and Potassium, the radiation from those radionuclides will significantly increase the emission of background radiation.

Gamma radiation is the prime concern for radiation protection (World Nuclear Association, WNA, 2010). The average effective dose from natural gamma rays is about $0.5 \mathrm{mSv}$ in a year. However, the dose varies with doses reaching as high as $260 \mathrm{mSv}$ in Northern Iran or $90 \mathrm{mSv}$ in Nigeria. Some people may receive doses a few times higher or lower than the average (IAEA, 2004; World Nuclear Association, WNA, 2010). The doses they receive are affected both by the geology of the area where they live and the structure of the buildings in which they live. Although the exposure from natural gamma radiation is generally quite low yet it is not entirely riskfree.

Generally, there is little that can be done to affect this dose from natural radiation, it would be sensible where possible to avoid building in locations or with materials with unusually high activity (IAEA, 2004). Therefore, the aim of this research is to investigate the level of gamma radiation from the asbestos ceilings of the hostels in the University of Maiduguri, Northeastern Nigeria. This will be done with a view to determining whether the level of gamma radiation in those hostels is within the permissible residential radiation level as specified by the International Committee for Radiological Protection, ICRP (2007). 


\subsection{Materials and Methods}

Maiduguri is located on the latitude $11^{\circ} .48^{1} \mathrm{~N}$ and longitude $13^{\circ} .12^{1} \mathrm{E}$ at an elevation of about $349.10 \mathrm{~m}$ above the sea level. University of Maiduguri is situated on the southern outskirts of Maiduguri, about twelve kilometres away from the centre of the city.

Measurements of gamma radiation level from the ceilings were made using RADEYE PRD manufactured by Thermo Scientific. It is a scintillation count-based survey meter that is highly sensitive to gamma radiation. The instrument used to perform the environmental survey is a RADEYE PRD by Thermo Scientific. It is a scintillation count based survey meter that is highly sensitive to gamma radiation. The instrument was calibrated at the National Institute of Radiation Protection and Research, a standard Institute certified by International Atomic Energy Agency (IAEA) and a division of the Nigerian Nuclear Regulatory Authority (NNRA). The characteristics features of this versatile new pocket meter are its portability, the ease and flexibility of its operation and superior measurement performance which is provided by the use of sophisticated low power technology.

Asbestos ceiling and non-asbestos (Gypsum) ceiling rooms were selected in Block B and C of the Boys' Hostels and New Faculty of Art Building respectively. Measurements of gamma radiation were performed by holding the survey at a distant of one (1) meter away from the ceiling. The measurement at each point is repeated three times in each of the rooms and the average is taken to represent the natural gamma radiation for each room. The dose rate in $\mu S v / h r$ was recorded for each room and the absorbed dose rate in $m S v / y e a r$ was computed using the relation below.

$$
D_{y}=A \times H \times Y \times 0.8
$$

where $D_{y}$ is the dose rate per year ( $m S v /$ year $), \mathrm{A}$ is the measured dose rate in $\mu \mathrm{Sv} / \mathrm{hr}, \mathrm{H}$ is the number of hours in a day (24 hours), $\mathrm{Y}$ is the number of days in a year (365 days) and 0.8 is the indoor occupancy factor. It is believed that an average person will spend about $80 \%$ of his/her time indoor and about $20 \%$ outdoor. Hence, the indoor occupancy factor is 0.8 while the outdoor occupancy factor is 0.2 .

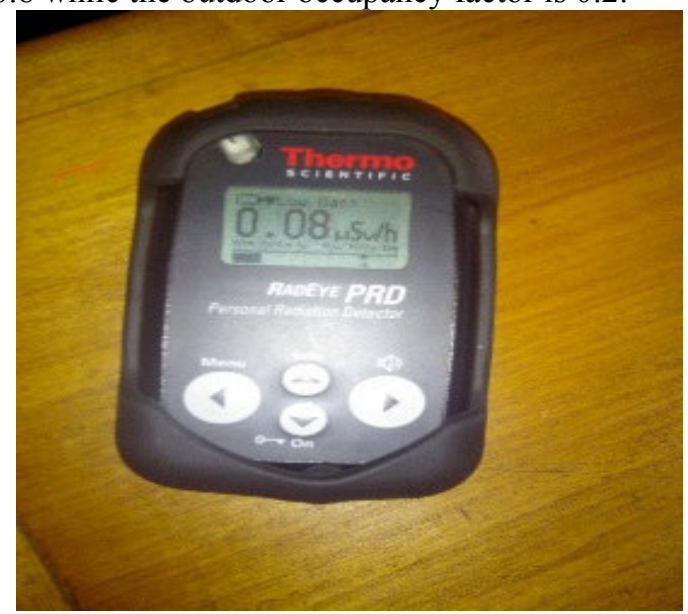

Figure 1: RADEYE PRD

\subsection{Results and Discussions}

Exposure of persons due to the presence of asbestos and non-asbestos ceiling was assessed and giving that exposure was uniformly distributed throughout the year based on 24 hours a day and 365days in a year. The estimated average annual gamma radiation readings and the annual average gamma radiation from asbestos and non-asbestos ceiling rooms (offices) within the University of Maiduguri are presented in tables 1 and 2 respectively.

Table 1: Shows the average measured and estimated Gamma radiation dose rate from asbestos ceiling rooms

\begin{tabular}{|c|c|c|}
\hline $\begin{array}{c}\text { Sample } \\
\text { Location }\end{array}$ & $\begin{array}{c}\text { Average Measured Dose Rate } \\
(\mu \mathrm{Sv} / \mathrm{hr})\end{array}$ & $\begin{array}{c}\text { Estimated Dose rate from Asbestos Ceiling Rooms } \\
(\mathrm{mSv} / \mathrm{yr})\end{array}$ \\
\hline $\mathrm{A}_{1}$ & 0.1 & 0.70 \\
\hline $\mathrm{A}_{2}$ & 0.1 & 0.70 \\
\hline $\mathrm{A}_{3}$ & 0.12 & 0.84 \\
\hline $\mathrm{A}_{4}$ & 0.11 & 0.77 \\
\hline $\mathrm{A}_{5}$ & 0.13 & 0.91 \\
\hline
\end{tabular}


Table 2: Shows the average measured and computed Gamma radiation dose rate from non-asbestos ceiling rooms.

\begin{tabular}{|c|c|c|}
\hline Sample Location & $\begin{array}{c}\text { Average Measured Dose } \\
\text { Rate }(\mu \mathrm{sv} / \mathrm{hr})\end{array}$ & $\begin{array}{c}\text { Estimated Dose from Non-asbestos (Gypsum) } \\
\text { Ceiling (mSv/yr.) }\end{array}$ \\
\hline $\mathrm{N}_{1}$ & 0.08 & 0.56 \\
\hline $\mathrm{N}_{2}$ & 0.07 & 0.49 \\
\hline $\mathrm{N}_{3}$ & 0.06 & 0.42 \\
\hline $\mathrm{N}_{4}$ & 0.06 & 0.42 \\
\hline $\mathrm{N}_{5}$ & 0.06 & 0.42 \\
\hline
\end{tabular}

In table 1, measurement locations $\mathrm{A}_{1}, \mathrm{~A}_{2}, \mathrm{~A}_{3}, \mathrm{~A}_{4}, \mathrm{~A}_{5}$, and $\mathrm{A}_{6}$ represent Students' hostel room $\mathrm{C} 2, \mathrm{C} 3, \mathrm{~B} 2, \mathrm{~B} 3$ and Common room respectively while in table $2, \mathrm{~N}_{1}, \mathrm{~N}_{2}, \mathrm{~N}_{3}, \mathrm{~N}_{4}$ and $\mathrm{N}_{5}$ represent office room number 144,145 , 146, 147 and 148 respectively at the New Faculty of Art. The estimated background radiation values indicate the environmental dose rate in $\mathrm{mSv} /$ year. The range of estimated gamma radiation from asbestos ceiling is 0.7 $0.91 \mathrm{mSv} / \mathrm{yr}$. while that of non-asbestos ceilings is $0.42-0.56 \mathrm{mSv} / \mathrm{yr}$.

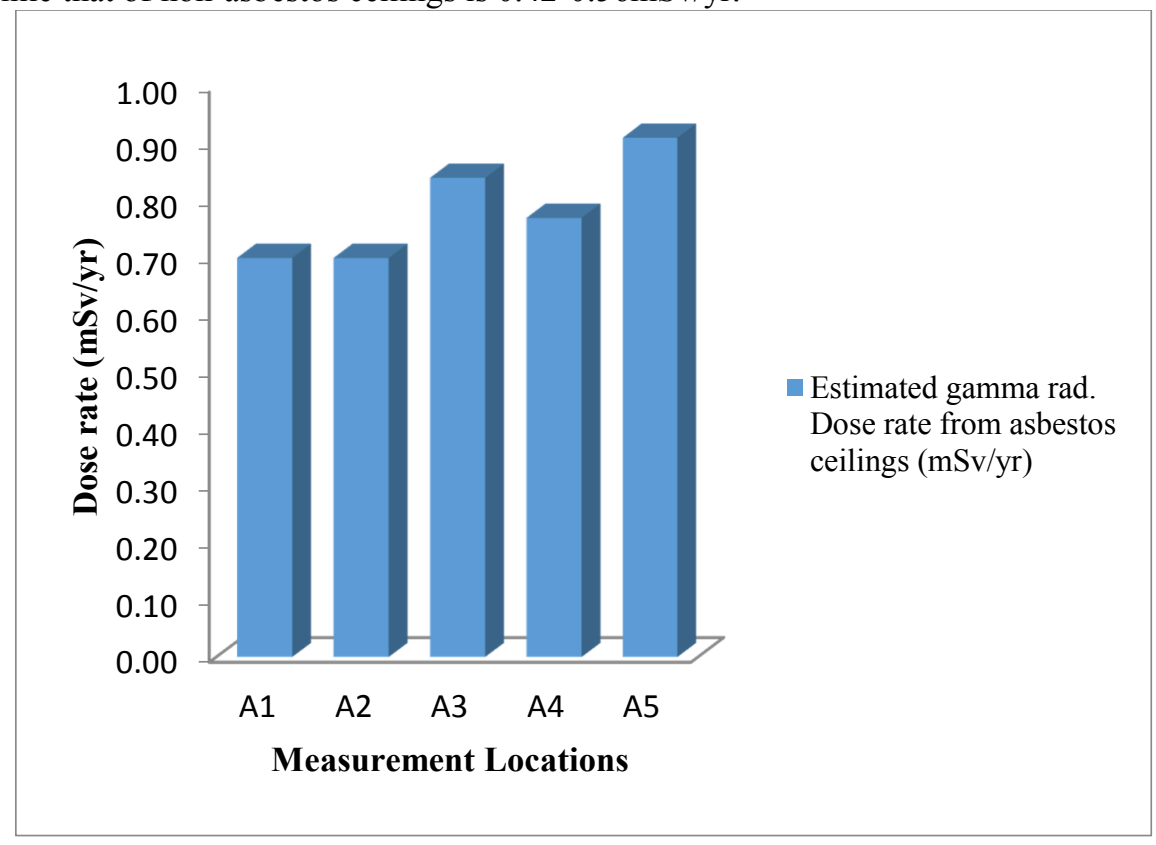

Figure 2: Graph of estimated gamma radiation dose rate against Hostel rooms with Asbestos Ceilings

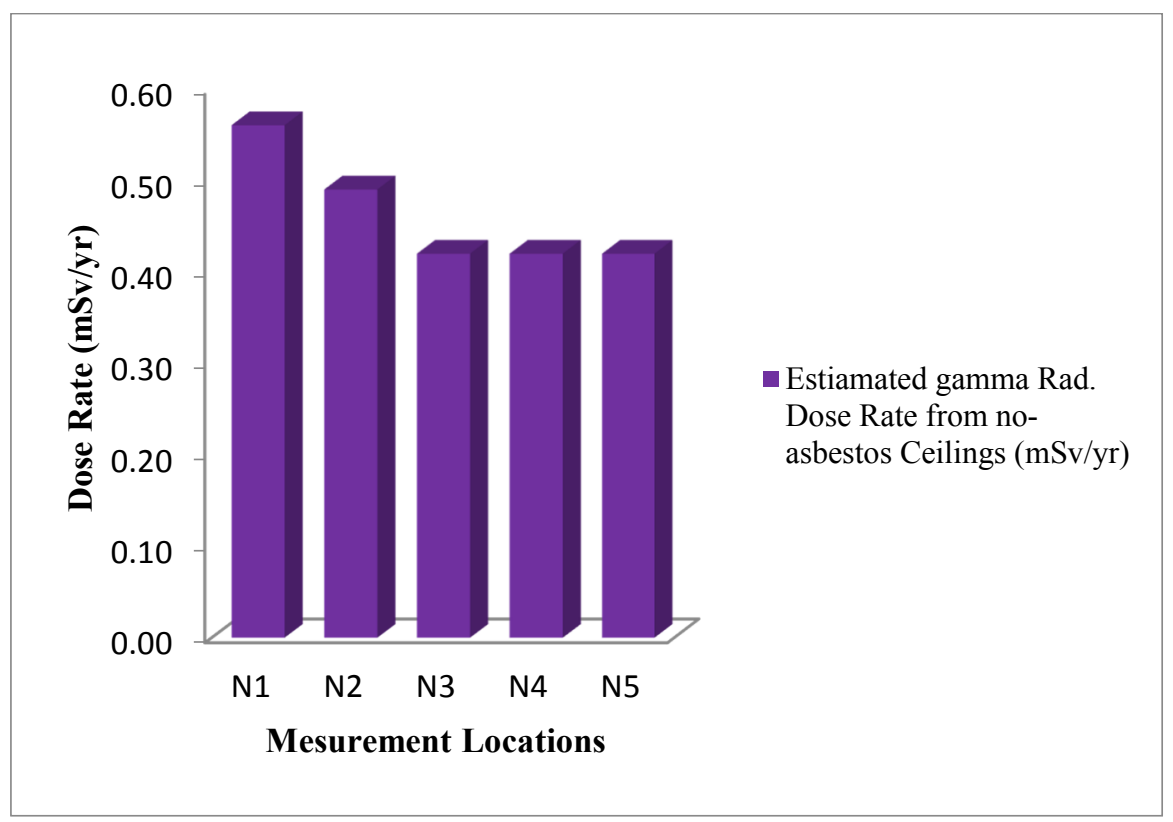

Figure 3: Graph of estimated gamma radiation dose rate against non-asbestos office ceilings. 


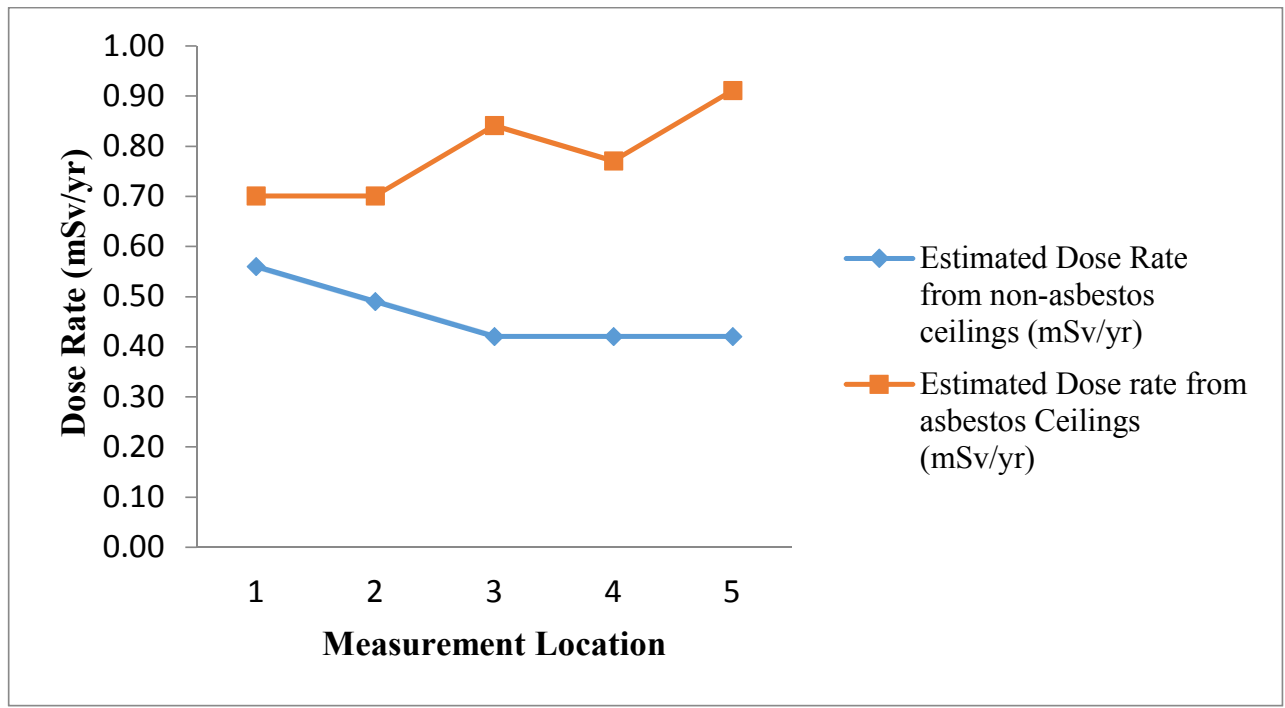

Figure 4: Graph comparing the estimated gamma radiation dose rate (mSv/yr) from non-asbestos ceiling rooms with asbestos ceiling rooms

Moreover, from the graphs in figure 2 and 3, it is clear that the measured and computed gamma radiations are slightly higher than the measured and computed background (environmental) radiation within the University of Maiduguri. The measured and computed gamma radiations from asbestos ceilings are significantly higher than those from the non-asbestos ceiling rooms (offices). The highest dose rate from asbestos ceiling room is $0.91 \mathrm{mSv} / \mathrm{yr}$. and it is from the Common Room in Block B $\left(\mathrm{A}_{5}\right)$ of the Boys' Hostel. It has asbestos ceilings and asbestos cement materials are used as sun rays shield. The least dose rate from asbestos ceilings room is $0.7 \mathrm{mSv} / \mathrm{yr}$. and this is from both room C1 and C2 of the C Block of the Students' Hostel. The graphs in figure 2 and 3 show the gamma radiation dose rate in $\mathrm{mSv}$ per year from asbestos and non-asbestos ceiling rooms respectively. Figure 4 compared the gamma radiation from the asbestos ceiling rooms with non-asbestos rooms and it clearly shows that gamma radiation from the rooms with asbestos ceiling, roof or shield is generally higher than rooms with nonasbestos ceilings.

Although asbestos fibres are not radioactive, the higher radiation around the asbestos in those rooms might be due to presence of primordial radionuclides of elements like ${ }^{238} \mathrm{U},{ }^{232} \mathrm{Th}$ and ${ }^{40} \mathrm{~K}$ in the soil where the asbestos were mined. Radiation protection standards assume that any dose of radiation, no matter how small, involves a possible risk to human health. However, available scientific evidence does not indicate any cancer risk or immediate effects at doses below $100 \mathrm{mSv}$ a year.

\subsection{Conclusion and Recommendation}

The highest annual effective dose rate due to gamma radiation is asbestos ceilings/materials in the Common Room of Boys' hostel in Block $\mathrm{C}$ and it is estimated to be $0.91 \mathrm{mSv}$ per year. This radiation dose is considered to be very low and almost insignificant to cause any serious health problems to the students living in the Hostel. Also, available scientific evidence does not indicate any cancer risk or immediate effects at doses below $100 \mathrm{mSv}$ a year (UNSCEAR, 2008). This is because, at low levels of exposure, the body's natural repair mechanisms seem to be adequate to repair radiation damage to cells soon after it occurs (World Nuclear Association, WNA, 2010). The only health risk might be due to the toxicity of the chemical constituents of asbestos ceilings/materials in the Block $\mathrm{B}$ and $\mathrm{C}$ of the Boys' Hostel within the University of Maiduguri rather than the radiological risks due to natural gamma radiation from the asbestos. The outcome of this research can be used in the compilation of background radiation map and radioelement mapping of Maiduguri.

\section{References}

Ademola, J.A., Adeyemo, O.A. (2006). Radiological exposure due to interlocking concrete floor tiles used in Ibadan city of Nigeria, Nigeria Journal of Science, 40, pp. 12-18.

ATSDR, (2001). Toxicological profile for asbestos (TP-61). US Dept. of Health and Human Services.

EPA, (2007). Ionizing Radiation Fact Book. USA Environmental Protection Agency, EPA-402-F-06-061.

Farai, I.P., Ojunakwe, C.E., Makinde, O.S. (2007). Gamma spectroscopic assay of soil samples from waste dump sites in Port Harcourt, Nigeria, Presented Paper at the ICRM Conference, Cape Town, South Africa.

HSE, (2005). Health and safety statistics, A National Statistics publication, UK

International Atomic Energy Agency, IAEA (2004). Radiation, People and the Environment (INIS-XA-703). Ford, 
J. (Ed.). International Atomic Energy Agency (IAEA) Publication, Vienna (Austria).

Myrick, T.E, Berven, B.A. and Haywood, F.F. (1983). Determination of the concentration of selected radionuclides in surface soil in USA. Health Phys., 45, pp.361.

Norbani, N.E., Salim, N. A., Abdul Rahman, A.T (2014). Measurement of terrestrial gamma radiation dose rate (TGRD) level in soil samples from the district of Rembau, Malaysia, using high-purity Germanium detectors. J. Phys.: Conf. Ser. $\mathbf{5 4 6} 012016$

NTP, (2005). NTP $11^{\text {th }}$ Report on Carcinogens Rep Carcinog, 111-A32 PM10: 19826456

Obed, R.I., Farai, I.P., Jibiri, (2005). Population dose distribution due to soil radioactivity concentration levels in 18 cities across Nigeria, Journal of Radiological Protegtion, 25, pp. 305-312.

Pastuszka, J. S. (2009). "Emission of Airborne Fibers from Mechanically Impacted Asbestos Cement Sheets and Concentration of Fibrous Aerosol in the Home Environment in Upper Silesia, Poland. Journal of Hazardous Materials, Vol. 162, No. 2-3, pp. 1171-1177.

USGS (2001). Some facts about asbestos (USGS fact sheets FS-012-01), 4 pp.

UNSCEAR (2008). Sources and Effects of Ionizing Radiation. United Nation Scientific Committee on Effects of Atomic Radiation, UNSCEAR Report, Volume 1.

Virta, (2006). Worldwide asbestos supply and consumption trends from 1900 through 2003. Reston, VA: US Geological Survey, circular 1298.

World Nuclear Association, WNA (2010). Nuclear Radiation and Health Effects. 